\title{
Experiências compartilhadas entre a História, o Ensino e as Novas Tecnologias Digitais
}

\author{
Israel Aquino ${ }^{1}$
}

Resumo: O presente trabalho produziu-se a partir das reflexões proporcionadas pela experiência durante a exposição "Alan Turing: legados para a computação e para a humanidade", dentro da disciplina de Estágio de Docência em História III da Faculdade de Educação da UFRGS. Sob a inspiração das propostas apresentadas pela exposição, que jogavam com questões sobre tecnologia dentro de uma instituição voltada ao patrimônio, buscamos aqui discutir as relações que se estabelecem e as possibilidades que se apresentam quando trabalhamos as relações entre patrimônio e tecnologia como forma de potencializar o trabalho do ensino de História, buscando dialogar com os principais referenciais acadêmicos dentro da academia brasileira contemporânea, em especial os estudos desenvolvidos por Ulpiano de Meneses e Vera Dodebei.

Palavras-chave: Ensino de história, Museus virtuais, Novas tecnologias.

Resumen: Este trabajo fue producido a partir de las reflexiones ofrecidas por la experiencia durante la exposición "Alan Turing: Legado para la informática y por la humanidad", dentro del curso de Docencia en Historia III de la Facultad de Educación de la Universidad Federal del Rio Grande del Sur. Bajo la inspiración de las propuestas realizadas por la exposición, que jugó con la tecnología dentro de una institución dedicada a el patrimonio, buscamos aquí hablar de las relaciones que se establecen y las posibilidades que surgen cuando trabajamos las relaciones entre el patrimonio y la tecnología con el fin de mejorar la enseñanza de la historia, buscando el diálogo con el principal referente académico en la academia brasileña contemporánea, especialmente los estudios desarrollados por Ulpiano de Meneses y Vera Dodebei.

Palabras-clave: Enseñanza de historia, Museos virtuales, Nuevas tecnologías.

${ }^{1}$ UFRGS 
Vivemos em um período onde as Tecnologias de Informação e Comunicação ${ }^{2}$ ganham enorme relevância, cumprindo um papel central em nosso dia-a-dia. Hoje nos vemos frente ao constante desafio de dominar recursos e ferramentas que nos são oferecidos em número cada vez maior, paulatinamente disputando a atenção de crianças, jovens e adultos enquanto canais de acesso à informação e ao conhecimento. Estamos em um momento em que a Internet está prestes a ultrapassar o papel desempenhado por outros meios de comunicação $^{3}$, transformando-se no veículo de comunicação contemporâneo por excelência. Nessa etapa de transição, novas formas de trocas e relacionamentos estão se estabelecendo, criando, segundo Ginzburg, uma sociedade com relações marcadas pelo imediatismo, pela virtualização e pela superficialidade (GINZBURG, 2010).

Nesse contexto, é presumível admitir que o ensino, bem como as relações nele envolvidas, são igualmente impactados por essa transformação cultural. Numa época em que nossas práticas habituais estão cada vez mais permeadas pela presença desses recursos e pela necessidade que temos de acesso a essas tecnologias, começam a se

\footnotetext{
${ }^{2}$ Os estudos dedicados ao surgimento e à aplicação destas tecnologias têm criado diferentes terminologias e nomenclaturas. Aqui, utilizaremos o termo Tecnologias de Informação e Comunicação, ou simplesmente TICs, tomando por referência a obra de Coll e Monereo (2011).

3 Algumas pesquisas demonstram que, entre o público mais jovem, a Internet está ultrapassando a TV enquanto instrumento de divulgação e acesso à informação. Um exemplo disso pode ser encontrado na pesquisa do Pew Research Center for the People \& the Press, Internet Gains on Television as Public's Main News Source, divulgada em 2010, que trata dessa questão em relação ao público jovem e adolescente dos Estados Unidos.
} 
tornar visíveis as transformações e contradições que atingem as relações de aprendizado, colocando-se como permanente desafio para educadores e profissionais do ensino o domínio deste instrumental tecnológico.

Por isso, com a ampliação das ações e iniciativas ligadas à educação patrimonial, procuramos nos colocar a questão de que lugar as instituições ligadas à preservação e exposição do patrimônio histórico devem ocupar em uma sociedade que se volta cada vez mais para o cibernético, em um mundo em que as representações virtuais vêm cada vez mais ganhando espaço no cotidiano das pessoas. "Das memórias analógicas passamos à memória virtual, e os museus - essencialmente instituições de memória - também vivem esse processo” (DODEBEI \& GOUVEIA, 2007: 94).

Ao caminharmos em direção ao espaço virtual, colocamos nossos objetos na ordem dos números e passamos da dimensão concreta para a abstrata - ou, como se costuma dizer, digital. Aos poucos, habituamo-nos a ver nossos conhecidos objetos analógicos sendo transformados em imagens digitais, apesar de guardarem as mesmas características da criação e da propriedade individual. As memórias, nesta fase, são duplicadas em um novo formato, com endereço próprio e uma visibilidade exponencial nunca antes imaginada. (DODEBEI \& GOUVEIA, 2007: 93)

Será, então, a era da Internet o prenúncio do fim para museus, arquivos e outras instituições do gênero? Ou, pelo contrário, nos encontramos num marco que aponta a possibilidade de se estabelecerem 
novas relações, potencializadas pela associação entre ensino, patrimônio e tecnologias?

O presente artigo produziu-se a partir das reflexões proporcionadas pela realização do estágio de docência em ensino de História na exposição "Alan Turing: legados para a computação e para a humanidade", dentro da disciplina de Estágio de Docência em História III da Faculdade de Educação da UFRGS. Sob a inspiração das propostas apresentadas pela exposição, que jogavam com questões sobre tecnologia dentro de uma instituição voltada ao patrimônio, buscamos aqui discutir as relações que se estabelecem e as possibilidades que se apresentam quando trabalhamos as relações entre patrimônio e tecnologia como forma de potencializar o trabalho do ensino de História.

\section{A experiência na exposição "Alan Turing"}

A experiência de estágio na exposição "Alan Turing...", do Museu da UFRGS, foi o mote inicial para o desenvolvimento deste trabalho. Nesta instituição, durante os meses de outubro e novembro de 2012, tivemos a oportunidade de nos envolver em atividades de planejamento, observação e mediação da exposição, ao mesmo tempo em que se nos apresentavam questões a respeito das relações entre ensino e patrimônio na disciplina de estágio.

A exposição "Alan Turing", que em sua concepção busca "captar a atenção do público jovem utilizando a ficção científica como 
uma interface entre os limites entre a realidade científica, a literatura e o cinema", organizou-se a partir da divisão de seu conteúdo em cinco partes, identificando as temáticas tratadas pela mesma. Entre estes, além do resgate da memória do próprio Turing, apresentam-se discussões acerca de temas como inteligência artificial, sua representação na literatura e no cinema, questões sobre tecnologia, robótica e a ética nelas envolvida, além das próprias concepções e limites da ciência - e em especial da matemática -, todas estas temáticas que estiveram presentes na vida e no trabalho de Turing.

Foi durante as oportunidades de mediação na exposição, enquanto discutimos com as crianças e jovens que visitavam o Museu, que nos surgiram as inquietações que motivaram este trabalho. Quais as relações que podem ser estabelecidas entre o patrimônio e a tecnologia como forma de potencializar o trabalho e o ensino em história? Buscando avançar na compreensão desta questão, procuramos pensar nossa atuação na mediação voltada para a problematização destes temas, buscando debater com os estudantes com os quais travamos contato.

Seria possível que a dicotomização entre museu e tecnologia venha sendo superada nos últimos anos? Em Porto Alegre, por exemplo, temos hoje o Museu de Ciência e Tecnologia da PUC-RS, inaugurado em 1998 e referência para muitos jovens que nasceram e cresceram na capital durante a última década. Contudo, como fica essa

\footnotetext{
${ }^{4}$ Trecho extraído da apresentação da exposição no site do Museu da UFRGS, em http://www.ufrgs.br/exposicao-alanturing/index.html. Acesso em 20/12/2012.
} 
questão para os jovens do interior? Durante nosso estágio, tivemos a oportunidade de atender diversas turmas do interior do estado, provenientes principalmente dos Institutos Técnicos e Tecnológicos Federais, e com essas turmas procurávamos fazer um trabalho de recepção à exposição fazendo o seguinte questionamento: qual a primeira coisa que lhe vem à cabeça quando falamos em Museus? E o que imaginamos encontrar quando nos dirigimos a um Museu?

Para o público que nunca travou contato com o MCT, a resposta que surgia mais naturalmente era: o museu como um local de exposição de objetos antigos, relacionados à história, de certa forma distante e separado do presente, da própria realidade em que se inseriam estas crianças e jovens. Porém, notamos que essa resposta não era tão automática quando trabalhávamos com crianças da capital.

Desta forma, podemos notar que a superação da dicotomia a que nos referíamos antes não é algo uniforme, e talvez nem seja a tendência dominante. A partir desse mote, sempre procuramos iniciar nossa mediação trabalhando com questões sobre o próprio conceito de patrimônio, as diferenças entre o patrimônio material e imaterial, e o museu em si como local de trocas e aprendizados, ao invés de simples depósito de "coisas velhas".

Em outro momento da exposição, tínhamos a oportunidade de problematizar questões sobre a própria concepção que a sociedade constrói acerca da tecnologia e de suas aplicações, quando discutíamos questões sobre a inteligência artificial e a robótica, sua representação no 
cinema e na literatura e as implicações éticas do seu desenvolvimento. Esta era uma das partes da exposição que mais suscitava o debate entre os alunos.

Buscávamos sempre traçar um paralelo entre os elementos da exposição e o cotidiano dos estudantes, relacionando a tecnologia apresentada nos filmes e na mídia com aquela presente em nosso dia-adia. Dessa forma, procurávamos demonstrar como essas questões, longe de serem distantes ou abstratas, estão muito presentes e tendem a ocupar um lugar cada vez mais central em nossas vidas, ao mesmo tempo em que se faz necessário refletir sobre as questões de ética que estão relacionadas.

Ao tratar de questões tão presentes e imediatas, e ao conseguir demonstrar como estas se inserem cada vez mais na vida destes estudantes, abria-se um amplo campo de debate, onde a participação destes se mostrava sempre recompensadora. De fato, ao discutir conceitos como inteligência artificial, liberdade e iniciativa, ou tratando de problemas como o desenvolvimento da robótica e as responsabilidades nela implicadas, conseguíamos despertar nestes estudantes o interesse por discutir questões que, ao mesmo tempo em que representam temas práticos de seu cotidiano, envolvem indagações teóricas muito mais profundas, como o direito à liberdade e o próprio conceito de humanidade, mas abordando estas de forma diferenciada, de uma maneira mais instigante para os estudantes.

Isto deixou-nos a impressão de que, pensada a partir destes 
momentos, a exposição e a forma como foi trabalhada demonstrava uma grande potencialidade para impulsionar uma série de relações que contribuíram para a apreensão de diversas questões envolvidas na temática da exposição por estes estudantes, mas de uma maneira diferente, que superou as formas de ensino tradicionais. E, nesse sentido, tanto a instituição e a noção de patrimônio a ela ligada, como a temática das tecnologias ligada à exposição, desempenharam papel importante. Mas, sendo assim, que outras possibilidades estas relações poderiam oferecer para o ensino? De que maneira o próprio ensino - e o ensino de história, que é nosso maior interesse aqui - poderia ser transformado, e quais os limites para essa contribuição, para essas trocas e interlocuções entre a tecnologia e o patrimônio na educação? Continuamos nossa reflexão tentando sugerir algumas respostas para estas questões.

\section{Relações entre tecnologia e patrimônio: desafios e potencialidades para o ensino}

Em outra oportunidade, na disciplina de Estágio em Docência em História no Ensino Médio, tivemos a oportunidade de realizar uma experiência com alunos de uma escola pública de Porto Alegre, acessando o site do Google Art Project ${ }^{5}$, que assim como outros projetos semelhantes, disponibiliza o acervo de diversas instituições

\footnotetext{
${ }^{5} \mathrm{http} / / / \mathrm{www} . g o o g l e a r t p r o j e c t . c o m / p t-b r /$
} 
museológicas na Internet para acesso livre e gratuito de seus usuários.

Esses museus no mundo virtual ${ }^{6}$, que no caso do projeto da empresa Google apresenta-se como versões virtuais de instituições que possuem também exposições "físicas". A ideia do projeto consiste em disponibilizar o acesso à representação iconográfica do acervo destas instituições, além de, em alguns casos, possibilitar uma "visita virtual" através do espaço físico da instituição, que é percorrido através de imagens quadro-a-quadro.

A experiência realizada na época mostrou-se bastante proveitosa. Para além da "novidade" com que se deparavam, sempre destacada pelos alunos, foi possível observar que os conteúdos trabalhados e exemplificados através da realização destas visitas "virtuais" aos acervos destas instituições eram sempre os mais lembrados pelos estudantes na avaliação final da disciplina. A ferramenta virtual, utilizada como auxiliar no trabalho de determinados

${ }^{6}$ De acordo com a tipologia criada por Maria Piacente (1996), citada por Rosali Henriques (2004) e Dodebei \& Gouveia (2007), podemos falar na existência de três diferentes tipologias para definir como se apresentam as instituições patrimoniais no espaço virtual: o folheto eletrônico, quando estas possuem apenas uma página de divulgação na Internet, com notícias, horários, etc., e que constitui a maior parte das páginas de museus na rede, incluído aqui o Museu da UFRGS; os museus no mundo virtual, onde a instituição física se projeta na virtualidade, havendo por vezes a possibilidade de visualização de acervos e exposições antigas, além de informações mais detalhadas - este seria o caso de projetos como o Google Art e o Era Virtual; e, finalmente, o que a autora chama de museus realmente interativos, onde a estrutura destes espaços permite uma interação efetiva do usuário e, além disso, comumente existem ações patrimoniais pensadas diretamente para o espaço virtual, ou seja, não se trata apenas de uma reprodução do espaço físico do museu - caso do Sagres (http://sagres.mct.pucrs.br/), o museu virtual do Museu de Ciência e Tecnologia da PUCRS, que atualmente encontra-se fora do ar. Contudo, é importante notar que essa é uma temática ainda muito nova, sendo essa conceituação ainda bastante discutida. 
conteúdos e problematizada em sala de aula junto aos estudantes mostrou-se eficaz como complementar ao trabalho do professor, na medida em que se demonstrou que a experiência produziu maior assimilação e interesse entre a turma ${ }^{7}$.

Mas este, é claro, é um relato de uma experiência isolada. Parece-nos que as relações entre ensino, história e tecnologias permanecem pouco problematizadas ainda hoje dentro do trabalho acadêmico brasileiro, tanto quanto nos parece necessário avançar nesta questão. Mas, se muito ainda nos falta para a construção de um corpus teórico que dê conta dessa temática, nos parece, por outro lado, perfeitamente possível apontarmos algumas possibilidades de trabalho.

Aparentemente, o primeiro desafio encontrado pelos profissionais em instituições e salas de aula refere-se à pouca familiaridade ou conhecimento das ferramentas e tecnologias disponíveis dentre o aparato tecnológico contemporâneo ${ }^{8}$. Esse tipo de dificuldade em relação ao uso e domínio das novas tecnologias geralmente contrasta com a atitude das gerações mais novas, que em geral apresentam grande facilidade no domínio destas tecnologias desde muito cedo, certamente pelo fato destas já fazerem parte, durante seu crescimento, do seu cotidiano; estes jovens e crianças vêm sendo chamados de "nativos digitais" (BENNETT et al., 2008). Isso coloca

\footnotetext{
${ }^{7} \mathrm{O}$ artigo produzido a partir desta experiência encontra-se em formato digital na Biblioteca Setorial da Faculdade de Educação da UFRGS.

${ }^{8}$ A esse respeito, podemos encontrar exemplos na dissertação de Marta Leivas (2004) e na obra de Coll e Monereo (2011), com os quais já travamos contato em trabalhos anteriores.
} 
como primeiro desafio o fato do educando ter maior domínio sobre esta possível ferramenta pedagógica do que o educador, o que sem dúvida gera desconfortos. Esse seria um momento ideal para estabelecer uma dinâmica de troca de conhecimentos, extrapolando a lógica do ensino tradicional, de maneira a possibilitar maior interação entre aluno e professor, mas sabemos que boa parte dos educadores ainda tem grandes dificuldades com este tipo de prática.

Por outro lado, percebemos que a apropriação destas tecnologias, quando ocorre, tem sido realizada de maneira a reforçar uma abordagem tradicional do ensino, em propostas que não diferem das práticas tradicionais e não colaboram para uma reciclagem destas, pois não ocorrem alterações de fundo no plano pedagógico, contribuindo para reforçar posturas de apropriação dos conteúdos sem a problematização e a reflexão necessárias. Assim, ocorre o alento do “caráter tradicional da educação, baseado na transmissão de conhecimentos para que os alunos os assimilem de forma passiva” (FRANÇA \& SIMON, 2008). A superação desse tipo de abordagem passa, em primeiro lugar, por uma formação inicial e contínua dos educadores, mas também por uma mudança nas concepções e práticas pedagógicas que norteiam sua atuação.

Essa situação nos parece recorrente também nas instituições museológicas, inclusive virtuais, que passam a utilizar essas ferramentas tecnológicas, mas carecem de maior problematização metodológica a fim de potencializar o uso de tais ferramentas para o 
ensino. Nesse caso, lembramo-nos do exemplo do Museu de Artes e Ofícios, de Minas Gerais, que faz parte do projeto Era Virtual, um projeto brasileiro que também é voltado para a exposição virtual dos acervos de diversas instituições brasileiras ${ }^{9}$. A instituição dispõe de vasto material fonográfico que é utilizado para a apresentação de sua exposição, estando este disponível tanto na visitação virtual como na presencial. Assim, sai de cena a figura do mediador e entra em cena uma narração mecânica da exposição, correndo-se o risco de "engessar" a mediação e perdendo-se a oportunidade de problematizar as diferentes temáticas abordadas, o que poderia trazer proveito muito maior para educandos e educadores. Nesse caso, é ressaltada a importância do papel do professor, a quem cumpre compensar essa deficiência, assumindo a tarefa de fomentar o debate e a discussão com a sua turma, seja visitando esta exposição presencialmente ou virtualmente.

Outro ponto preocupante, segundo aponta Ulpiano Menezes (2007), é a multiplicação de dados na chamada Sociedade da Informação, que muitas vezes implica em uma apreensão rasa e superficial, em detrimento da construção de novos conhecimentos. Esse excesso de conteúdo informacional deixa os indivíduos sem foco, redundando em saturação. Segundo o autor, a hiperinformação gera desinformação (MENEZES, 2007). Ao mencionar os museus virtuais ${ }^{10}$,

\footnotetext{
${ }^{9}$ http://www.eravirtual.org/pt/

${ }^{10}$ Deleuze (1996) afirma que o virtual não se opõe ao real, mas existe como uma parte de real, como se todo o objeto tivesse duas partes coexistentes, e ainda como uma potência do real. Entendemos aqui, também, o virtual como uma representação do real, sendo sua existência interdependente. $\mathrm{O}$ entendimento deste conceito implica a
} 
o autor defende que estes precisam ser desnaturalizados e problematizados, para que através do distanciamento necessário possa haver o discernimento e a apreensão do conhecimento. A virtualização das instituições é um dos caminhos possíveis para a preservação do patrimônio da memória, mas não necessariamente a mais correta, e certamente não é a única, nem é substitutiva de outras formas de preservação (Idem). Porém, Ulpiano não se opõe estritamente a esta tendência: aceita-a, mas também procura problematizá-la, ressaltando ainda que "é preciso fazer do virtual um território de exploração e não de rendição incondicional ou de sedução consentida” (MENEZES, 2007).

Ulpiano aponta, ainda, que tais ferramentas tecnológicas não são dotadas de autonomia ou valor imanente, mas adquirem valor para a preservação do patrimônio e para o ensino a partir do momento em que contribuem para a ampliação e potencialização do ensino patrimonial, e para isso é fundamental o trabalho crítico. Contudo, quando este ocorre abrem-se possibilidades extraordinárias para a ação de professores e de instituições (MENEZES, 2000: 100-101).

Dodebei e Gouveia (2007) também apontam o ganho significativo que podem apresentar estas tecnologias, principalmente porque a partir dos processos de digitalização foi possível ampliar enormemente a recuperação de informações e sua conservação.

valorização da própria noção de museu virtual ou virtualizado, de modo que essa categoria não se oporia aos museus formalmente constituídos, mas poderia representar uma ampliação espacial desse tipo de instituição (DODEBEI \& GOUVEIA, 2007: 95). 
Contudo, também indicam que o próprio processo de digitalização, por si só, não deve ser um fim em si, assim como não produz mudanças sozinho.

Fica explícito que a digitalização de acervo não transforma necessariamente um museu em um museu virtual. O processo de virtualização se dá quando a instituição torna disponíveis essas e outras informações por meio de seu website - o que também não é o mesmo que dizer que esta é uma instituição virtual. A virtualização é aqui entendida como o processo, mas o virtual diz mais respeito à própria tipologia do museu, da composição física de seu acervo e da especificidade das suas exposições. (GOUVEIA \& DODEBEI, 2007: 96)

Ainda nesse sentido, Dodebei (2011) aponta que a virtualização dessas instituições implica no surgimento de novos processos de subjetivação, apropriação e uso das narrativas, no momento em que o espaço virtual se transforma ele próprio em um lugar de memória, para usar a classificação de Pierre Nora. A autora demonstra também preocupação com o fato de não haver grande esforço no sentido de promover a proteção e a qualidade desses processos de digitalização, havendo, isso sim, maior esforço por garantir a acumulação e a velocidade do acesso à informação, mas sem os necessários critérios de qualidade, como já apontava Menezes.

Por outro lado, Rosali Henriques indica que a Internet possibilita, através das chamadas visitas virtuais, uma maior visibilidade das instituições patrimoniais, podendo atrair um público maior para as exposições presenciais. Ao transformar "átomos em bits", 
o mundo virtual permite aproximar a instituição de uma nova geração cada vez mais "virtual", auxiliado pelo fato de que "o museu na Internet nunca fecha" (HENRIQUES, 2004). Henriques destaca também a oportunidade que a Internet oferece para a construção de parcerias entre diferentes instituições, possibilitando a construção de exposições compartilhadas em construções interinstitucionais, lamentando, porém, as poucas realizações que existem nesse sentido (Idem). Em suma, podemos ver que os autores consultados não negam a potencialidade oferecida pela parceria entre tecnologias e instituições de patrimônio, e as possibilidades que daí surgem para o ensino, porém não a superestimam, buscando sempre chamar a atenção para a necessidade de uma apropriação crítica, que estimule a produção de conhecimento a partir de uma postura analítica e problematizadora.

Entendemos que, no plano educacional, a superação desses obstáculos se vincula principalmente à adoção de uma postura crítica e comprometida por parte de educadores e educadoras. A implementação de estratégias pedagógicas que envolvam essas Tecnologias de Informação e Comunicação requer a adoção de posturas que permitam a adaptabilidade e a cooperação. Mas não se trata de colocar em questão a presença dessas tecnologias em sala de aula, mas sim a extensão e o sentido de sua presença. A chave não está, em nosso entendimento, em comparar a utilização destas ferramentas com o ensino tradicional, tentando estabelecer as vantagens e inconvenientes de um e outro. Em vez disso, melhor seria pesquisar como podemos utilizar essas 
tecnologias para promover a aquisição e o desenvolvimento de novas competências.

Portanto, entendemos que no ensino, assim como na pesquisa, a adoção deste instrumental tecnológico requer a adoção de uma postura crítica e coerente, mas que ao mesmo tempo permita a evolução e qualificação de nosso trabalho. Acreditamos que essa parceria apresenta forte potencial no sentido de ampliar as possibilidades do ensino e contribuir inclusive para promover algumas transformações nas habituais relações escolares. A mudança de papéis decorrentes das formas de apropriação dessas ferramentas possibilita, também, que educadores e educadoras sejam impelidos à pesquisa e à reflexão, a fim de responder às novas demandas que surgem nos espaços de aprendizado - presenciais ou não.

\section{Considerações Finais}

Como aponta Peter Van Mensch (2009), “a tecnologia moderna parece oferecer novas possibilidades não só para aumentar o acesso e a interpretação, mas também para fazer uma ponte entre a memória histórica e a memória coletiva [...]”. A proliferação das tecnologias digitais traz para o trabalho com o patrimônio e para a educação patrimonial novas perspectivas, não somente por permitir potencializar o acesso aos museus, mas também por dar oportunidade aos museus de saírem de seus muros, conforme aponta Henriques (2004). Contudo, essas tecnologias não vêm para substituir ou anunciar 
o fim das instituições tradicionais, mas quiçá para potencializar uma nova perspectiva de interação com o patrimônio.

Temos várias pistas dos caminhos a percorrer para chegar a esse objetivo. Como aponta Magaly Cabral (2004), “devemos buscar metodologias que permitam [...] a ressignificação cultural $e$ a reformulação de discursos pelo museu, pelo professor e pelo público visitante, [...] [buscando assim alcançar] a democratização do museu”. Para tanto, é essencial que o educador e o profissional das instituições de patrimônio encarem as novas tecnologias como ferramentas com grande potencial inovador, que trazem novas possibilidades para a educação patrimonial, mas que ao mesmo tempo procurem manter uma postura crítica e problematizadora, para que a apropriação destas novas tecnologias possa cumprir no ensino seu pleno potencial.

Finalmente, entendemos que todo esse potencial transformador está condicionado pelas apropriações que forem feitas e pelas relações conscientes que forem estabelecidas nesse processo. $\mathrm{O}$ sucesso de tal empreitada depende da postura adotada por seus atores. Nesse sentido, temos claro que é preciso respeitar o conhecimento alheio, buscar aperfeiçoamento e incentivar a curiosidade. O novo não traz respostas por si: é preciso refletir sobre ele, buscar, pensar, pesquisar. O papel de educadores e pesquisadores continua sendo $\mathrm{o}$ de construir $\mathrm{o}$ conhecimento através de uma postura crítica, coerente e comprometida; o conhecimento continua um produto da ação consciente e da reflexão humana. 


\section{Referências}

ALMEIDA, Fábio Chang. O Historiador e as Fontes Digitais: uma visão acerca da internet como fonte primária para pesquisas históricas. Aedos - Revista do Corpo Discente do Programa de Pós-Graduação em História da UFRGS, v. 3, p. 9-30, 2011. Disponível em: <http://seer.ufrgs.br/aedos/article/view/16776/11939>. Acesso em 25/02/2016.

ARRUDA, Eucidio Pimenta. Museu Virtual, Prática docente e ensino de história: apropriações dos professores e potencialidades de elaboração de um museu virtual orientado ao visitante. In: Anais Eletrônicos do IX Encontro Nacional dos Pesquisadores do Ensino de História. em: $<$ http://abeh.org/trabalhos/GT01/tcompletoadriana.pdf>. Acesso em 25/02/2016.

BENETT, S.; MATON, K.; KERVIN, L. The 'digital natives' debate: A critical review of the evidence. British Journal of Educational Technology, n. 39 (5), p. 775-786, 2008. Disponível em: <http://onlinelibrary.wiley.com/doi/10.1111/j.1467-

8535.2007.00793.x/abstract;jsessionid=56FB431A10BD0C40EA691C CE29024A50.d03t03>. Acesso em 25/02/2016.

CABRAL, Magaly. Museus e o patrimônio intangível: o patrimônio intangível como o veículo para a ação educacional e cultural. MUSAS Revista Brasileira de Museus e Museologia do IPHAN, Rio de Janeiro, v. 1, n. 1, p. 49-59, 2004. Disponível em: <http://www.icom.org.br/A_prod_intelec_CECABrasil_conf_intern.pdf>. Acesso em 25/02/2016.

COLL, C. \& MONEREO, C. Psicologia da Educação Virtual: aprender e ensinar com as tecnologias da informação e da comunicação. Porto Alegre: Artmed, 2010. 
CORRÊA, D. \& SCHULZ, M. Conhecimento histórico e Internet: uma conversa com Carlo Ginzburg. Aedos - Revista do Corpo Discente do Programa de Pós-Graduação em História da UFRGS, v. 3, p. 9-30, 2011. Disponível em: <http://seer.ufrgs.br/aedos/article/view/20722>. Acesso em 25/02/2016.

DELEUZE, Gilles. O atual e o virtual. Em: Filosofia

Virtual. São Paulo: Editora 34, 1996. p. 49-56.

DODEBEI, Vera. Memória e patrimônio: perspectivas de acumulação/dissolução no ciberespaço. Aurora - Revista de Arte, Mídia e Política, São Paulo, n. 10, p. 36-50, 2011. Disponível em: <http://revistas.pucsp.br/index.php/aurora/article/view/4614>. Acesso em 25/02/2016.

DODEBEI, Vera; GOUVEIA, Inês. Memórias de pessoas, de coisas e e computadores: museus e seus acervos no ciberespaço. MUSAS Revista Brasileira de Museus e Museologia do IPHAN, Rio de Janeiro, n. 3, p. 93-100, 2007. Disponível em: <http://www.museus.gov.br/wp-content/uploads/2011/01/Musas3.pdf>. Acesso em 25/02/2016.

FRANÇA, C. \& SIMON, C. Como conciliar ensino de história e novas tecnologias?. Anais do VII Seminário de Pesquisa em Ciências Humanas. Londrina: Eduel, 2008. Disponível em: $<$ http://www.uel.br/eventos/sepech/arqtxt/resumosanais/CyntiaSFranca.pdfhttp://www.uel.br/eventos/sepech/arqtxt/resumos -anais/CyntiaSFranca.pdf>. Acesso em 25/02/2016.

FERREIRA, Luzia \& MELO, Diogo. Museus, ciência e tecnologia. Bol. Mus. Para. Emílio Goeldi. Cienc. Hum., Belém, v. 6, n. 1, p. 245-248, 2011. Disponível em: <http://www.scielo.br/scielo.php?script=sci_arttext\&pid=S198181222011000100018>. Acesso em 25/02/2016. 
GINZBURG, Carlo. História na era Google. Conferência proferida no Seminário Internacional Fronteiras do Pensamento - 2010. Disponível em <http://www.youtube.com/watch?v=wSSHNqAbd7E>. Acesso em 25/02/2016.

GRINBERG, Keila. A História que está na moda: divulgação científica, ensino de História e Internet. Disponível em: $<$ http://cafehistoria.ning.com/profiles/blogs/arquivo-cafe-historia-a168>. Acesso em 25/02/2016.

HENRIQUES, Rosali. Museus Virtuais e cibermuseus: a Internet e os museus. Disponível em: <http://memoria.petrobras.com.br/artigos-epublicacoes/museus-virtuais-e-cibermuseus\#.UORmz-R9KGJ>. Acesso em 25/02/2016.

LEIVAS, Marta. Riscos \& Bordados: o ensino de História e as tecnologias de informação e comunicação. 2004. 142f. Dissertação (Mestrado em Educação) - Faculdade de Educação, UFRGS, Porto Alegre, 2004.

Disponível em: <http://www.lume.ufrgs.br/bitstream/handle/10183/5834/000432212.pd f? sequence $=1>$. Acesso em 25/02/2016.

MENEZES, Ulpiano. Educação e museus: sedução, riscos e ilusões. Ciências e Letras - Revista da Faculdade Porto-Alegrense de Educação, Ciências e Letras, Porto Alegre, n. 27, p. 91-101, 2000.

. Os museus na era virtual. XVI Seminário Internacional Museus, Ciência e Tecnologia, Rio de Janeiro: MNH, 2007.

- Para que serve um museu (entrevista). Revista de História da Biblioteca Nacional. Disponível em: <http://www.revistadehistoria.com.br/secao/entrevista/ulpiano-toledobezerra-de-meneses>. Acesso em 25/02/2016. 
Pew Research Center for the People \& the Press. Internet Gains on Television as Public's Main News Source. 2010. Disponível em: $<$ http://www.people-press.org/2011/01/04/internet-gains-on-televisionas-publics-main-news-source/http://www.peoplepress.org/2011/01/04/internet-gains-on-television-as-publics-mainnews-source/>. Acesso em 25/02/2016.

SÁ, Antônio F. A. Admirável campo novo: o profissional de história e a Internet. Revista Eletrônica Tempo Presente. Disponível em: <http://www.tempopresente.org/index.php?option=com_content\&view $=$ article \&id $=3620 \% 3$ Aadmiravel-campo-novo-o-profissional-dehistoria-e-a-internet\&catid=222\&Itemid $=100076 \& l a n g=p t>$. Acesso em 25/02/2016.

TIMÓTEO, Herbert. A potencialidade dialógica das tecnologias de informação e comunicação no ensino e aprendizagem de história. Anais Eletrônicos do IX Encontro Nacional dos Pesquisadores do Ensino de História. Disponível em: <http://abeh.org/trabalhos/GT01/tcompletoherbert.pdf >. Acesso em 25/02/2016.

VALENTE, José Antonio. O uso inteligente do computador na educação. Pátio, Ano 1, n. ${ }^{\circ}$ 1, Artes Médicas Sul, 1997. p. 19-21.

VAN MENSCH, Peter. Notas sobre os arredores: patrimônio e novas tecnologias. MUSAS - Revista Brasileira de Museus e Museologia do IPHAN, Rio de Janeiro, n. 4, p. 11-23, 2009.

Artigo recebido em25/02/2016, aceito em 09/05/2016 